\title{
AR37 endophyte effects on porina and root aphid populations and ryegrass damage in the field
}

\author{
A.J. POPAY ${ }^{1}$, B. COTCHING ${ }^{2}$, A. MOORHEAD ${ }^{2}$ and C.M. FERGUSON ${ }^{3}$ \\ ${ }^{1}$ AgResearch, Ruakura Research Centre, Private Bag 3123, Hamilton \\ ${ }^{2}$ Agricom, PO Box 3761, Christchurch \\ ${ }^{3}$ AgResearch, Invermay Agricultural Centre, Private Bag 50034, Mosgiel \\ alison.popay@agresearch.co.nz
}

\begin{abstract}
The novel endophyte, AR37, in ryegrass has reduced porina larval survival and plant damage in pot trials. To determine the effect of AR37 on larvae in the field, populations were estimated in two ryegrass field trials in Canterbury. Plant damage and plant densities were also scored in one trial. At Ceres Farm, no porina were found in Italian ryegrass 'Status' infected with AR37 whereas low populations $\left(<10 \mathrm{~m}^{-2}\right)$ were present in endophyte-free and AR1-infected ryegrass of the same cultivar. In the third year of an endophyte ryegrass trial near Oxford, density of porina tunnels was $60 \%$ lower in the tetraploid perennial ryegrass 'Halo' with AR37 than in 'Bealey' with NEA2. In the diploid perennial ryegrass cultivars, 'Commando' and 'One50', porina populations were $81-84 \%$ lower in AR37-infected plots compared with the same cultivars infected with AR1or with low level Wild-type infection. Plant damage was on average $71 \%$ lower and plant densities $63 \%$ higher in AR37 than in the AR1 and low endophyte treatments.

Keywords: tetraploid, diploid, Wiseana, root aphid, AR1, NEA2
\end{abstract}

\section{Introduction}

Porina (Wiseana spp.) is a major endemic pest in pastures in the southern North Island and many parts of the South Island. High populations can also occur in more northern districts, as has been found on farms recently developed from forestry near Tokoroa (C.M. Ferguson, unpublished data). Seven species of porina have been described (Dugdale 1994) which vary in their phenology and therefore in the times of the year when damage occurs. Species diversity appears to be greatest in the southern South Island, resulting in the potential for damage to occur over many months of the year (Barratt et al. 1990).

Porina have an annual lifecycle. Moths are short lived but capable of laying large numbers of eggs (estimates of 780-1700 were made by Pottinger (1968)) which are often distributed over pasture as they fly. Larvae live for about 6 weeks on the surface of the pasture before forming burrows in the ground from which they emerge to feed on herbage. It is considered to be a denuding pest because herbage removal increases with increasing herbage mass up to $2000 \mathrm{~kg}$ /ha dry matter (Barlow 1985a). This makes them much more destructive than grazers which remove a constant amount of plant material regardless of herbage available. Porina feeding removes pasture at ground level, leaving large bare areas which become colonised by weeds. They readily feed on both white clover (Trifolium repens) and ryegrass (Lolium perenne), growing equally well on these major components of improved pasture (Farrell et al. 1974).

Jensen \& Popay (2004) reported that AR37, a novel fungal endophyte (Neotyphodium lolii) strain infecting perennial ryegrass (Lolium perenne), significantly reduced feeding and survival of porina ( $W$. cervinata) larvae compared with ryegrass infected with AR1 or Wild-type endophyte, or endophyte-free ryegrass in two laboratory trials. To verify that AR37-infected ryegrass reduces porina populations and plant damage in the field, the opportunity was taken to sample two trials in Canterbury which were set up to compare different ryegrass lines. Soil sampling of one of these trials showed there were also infestations of a root aphid, Aploneura lentisci, present. This sap-sucking insect originates from the Mediterranean but has been present in New Zealand for many years, although it was thought to be of no economic significance (Cottier 1953). This paper reports on infestations of porina and A. lentisci in these trials.

\section{Methods}

\section{Ceres Farm, Canterbury}

The Ceres Farm trial near Prebbleton was situated on a Waimakariri silt loam soil. The site is $40 \mathrm{~m}$ a.s.l. with an average annual rainfall of $622 \mathrm{~mm}$. Irrigation was occasionally applied during the summer. Average daily temperatures vary between 12.1 and $22.3^{\circ} \mathrm{C}$ in January and 0.7 and $10.7^{\circ} \mathrm{C}$ in July, with frosts a common occurrence between May and September. The trial, which was evaluating a range of cultivars, was planted in March 2006 at a sowing rate of $20 \mathrm{~kg} / \mathrm{ha}$. Plot size was $5 \mathrm{~m} \times 1.5 \mathrm{~m}$ with four replicates of each treatment. Yields were measured by mowing strips and then the trial was levelled by mower, with sheep occasionally 
used to clean up after yield measurements and prior to mowing. Nitrogen was applied at a rate of $3 \%$ of the mean dry matter yields removed.

In this trial, Italian ryegrass (L. multiflorum) 'Status' infected with AR1, AR37 or without endophyte (Nil) was sampled in early August 2007 by taking six spade squares $(200 \times 200 \mathrm{~mm}$ to a depth of $150 \mathrm{~mm})$ at random within each plot. This cultivar was the only one in the trial infected with both AR1 and AR37. Soil was hand sorted and porina larvae were counted. Root aphid was also present and the number of colonies (clusters of white wax inhabited by live aphids) observed in each spade square was counted.

At the same time as the insect sampling, 20 tillers were taken from each plot and tested for endophyte by immunoblot.

\section{Woodstock, Canterbury}

A tetraploid and a diploid ryegrass trial were located near Oxford at $300 \mathrm{~m}$ a.s.l. on a Hororata stony silt loam soil in an area with dry summers and occasional north-westerly rainfall. Frosts are common and snow settles in the area at least once per year.

The trials were conventionally drilled on 13 October 2008 with $250 \mathrm{~kg} / \mathrm{ha}$ DAP into a cultivated seedbed at a sowing rate of $22 \mathrm{~kg} / \mathrm{ha}$ for the diploid treatments and $28 \mathrm{~kg} / \mathrm{ha}$ for the tetraploids. Plot size was $5 \mathrm{~m} \times 1.5 \mathrm{~m}$ with four replicates of each treatment in a randomised block design. The tetraploid trial, adjacent to the diploid trial, comprised two cultivar/endophyte combinations, 'Halo' infected with AR37 and 'Bealey' infected with NEA2. The diploid treatments were 'Alto', 'Arrow', 'Commando', 'One50' and 'Revolution' infected with AR1, 'Commando' and 'One50' infected with AR37 and 'One50' with a low level of infection by Wild-type endophyte. Herbicides were applied at establishment to control broadleaf weeds and occasionally thereafter as necessary. Yield assessments were made by mowing the whole plot except on three occasions when measurements were taken from $2.25 \mathrm{~m}^{2}$ in each plot, before the trial was grazed with dairy heifers and then mown to an even post-grazing residual. After each assessment, nitrogen was applied at a rate calculated to be approximately $3 \%$ of the mean dry matter yield of the cut. Fertiliser was applied in the form of urea, Nitrophoska Blue TE and Cropmaster 15.

Porina populations were estimated by counting tunnels in six $200 \times 200 \mathrm{~mm}$ quadrats thrown randomly within each plot in July 2011. Assessments were made on two tetraploid endophyte combinations, 'Bealey' NEA2 and 'Halo' AR37, and two diploid cultivars with different endophyte treatments; 'One50' infected with AR1, AR37 or with a low rate of endophyte infection with the Wild-type strain (LE) and 'Commando' infected with AR1 or AR37. In addition, plant damage on 10 randomly selected plants in each plot of each treatment within the trial was scored on a scale of $0-3$ where $0=$ no damage and $3=$ severe damage (plant alive with most of the herbage removed or plant dead). Each plot was also visually scored for plant density on a scale of 1-5 where 5 had the highest density.

Endophyte infection levels were determined by immunoblotting 20 tillers taken from each replicate plot of the 'Halo', 'Bealey', 'One50' and 'Commando' treatments.

\section{Statistical analyses}

In all trials, insect data were converted to density estimates and analysed by an analysis of variance. Data on porina and root aphid numbers in the Ceres Farm trial were square root transformed prior to analysis while data in the Woodstock trials did not require transformation. Plant damage and plant density scores were analysed using the Restricted Maximum Likelihood Estimation (REML) for analysis of linear mixed models.

\section{Results \\ Ceres Farm Trial}

More than $80 \%$ of tillers in 'Status' AR1 and AR37 plots were infected with endophyte and less than $10 \%$ in Nil treatments (Table 1). No porina were found in AR37 plots and populations were low $\left(8-9 \mathrm{~m}^{-2}\right)$ in AR1 and Nil plots, but significantly greater than in

Table 1. Endophyte infection rates and densities of porina and root aphid colonies in Italian ryegrass 'Status' without endophyte (Nil) or infected with AR1 or AR37 in the Ceres Farm trial sampled in August 2007.

\begin{tabular}{lccccc}
\hline Endophyte & \% Endophyte & \multicolumn{2}{c}{$\begin{array}{c}\text { Porina larvae } \\
\left(\text { No. } \mathrm{m}^{-2}\right)\end{array}$} & \multicolumn{2}{c}{$\begin{array}{c}\text { Root aphid colonies } \\
\left(\text { No. } \mathrm{m}^{-2}\right)\end{array}$} \\
& & Actual & Sqrt & Actual & Sqrt \\
\hline AR1 & 96 & 8 & 1.390 & 458 & 21.30 \\
AR37 & 80 & 0 & 0 & 106 & 10.10 \\
Nil & 9 & 9 & 1.457 & 403 & 19.10 \\
SED & & & 0.207 & 2.96 \\
P & & & $<0.001$ & & 0.02 \\
\hline
\end{tabular}


AR37 $(\mathrm{P}<0.001)$ (Table 1). Fewer $(\mathrm{P}<0.02)$ root aphid colonies were found in AR37 plots compared with AR1 and Nil.

\section{Woodstock Trials}

Endophyte infection levels were high $(>75 \%)$ in 'Halo', 'Bealey', 'Commando' and 'One50' with AR1 and AR37 and low (19\%) in 'One50' LE (Table 2), all sampled at the same time as porina were assessed. Endophyte infection levels with AR1 in 'Alto', 'Arrow' and 'Revolution' were not determined at the time of the porina evaluation but had been determined in a similar trial planted at the same time at Riversdale in Southland using the same seed lines. Immunoblotting of at least 50 tillers of each of these treatments showed all had high $(>80 \%)$ endophyte infection rates.

In the tetraploid treatments, 'Halo' AR37 had a lower $(\mathrm{P}<0.028)$ porina density compared with 'Bealey' NEA2 based on the number of tunnels found (Fig. 1). This was reflected in a lower $(\mathrm{P}<0.001)$ plant damage score and a higher $(\mathrm{P}<0.001)$ plant density score for AR37 than for NEA2 (Table 2).

In both diploid cultivars, 'Commando' and 'One50', infected with AR37, the estimated porina density was lower $(\mathrm{P}<0.001)$ than in AR1 and LE (Fig. 1). AR1 and LE treatments had similar porina populations. In AR37 plots, feeding damage to plants was lower and plant density scores higher compared with the AR1 treatments in the different cultivars, and compared with

Table 2. Percent endophyte infection levels, average porina feeding damage/plant and density score/ plot in tetraploid and diploid perennial ryegrass infected with different endophytes in two trials at Woodstock in Canterbury, sampled in July 2011

\begin{tabular}{lccc}
\hline Treatment & $\begin{array}{c}\text { \% Endo- } \\
\text { phyte }\end{array}$ & $\begin{array}{c}\text { Feeding } \\
\text { damage/plant }\end{array}$ & $\begin{array}{c}\text { Plant } \\
\text { density/plot }\end{array}$ \\
\hline Bealey NEA2 & 85 & 1.75 & 2.75 \\
Halo AR37 & 82 & 0.70 & 4.50 \\
SED & & 0.189 & 0.250 \\
$\mathrm{P}$ & & 0.012 & 0.006 \\
& & & \\
Alto AR1 & $83^{1}$ & 1.90 & 2.00 \\
Arrow AR1 & 82 & 1.63 & 2.00 \\
Commando AR1 & 85 & 1.65 & 1.50 \\
Commando AR37 & 75 & 0.55 & 4.50 \\
One50 AR1 & 93 & 1.78 & 2.25 \\
One50 AR37 & 85 & 0.55 & 4.75 \\
One50 LE & 19 & 2.08 & 1.50 \\
Revolution AR1 & 94 & 1.65 & 2.50 \\
SED & & 0.151 & 0.518 \\
P & & $<0.001$ & $<0.001$ \\
\hline
\end{tabular}

${ }_{1}^{1}$ Percent endophyte infection levels given in italics are based on infection levels in another trial that used the same seed line.

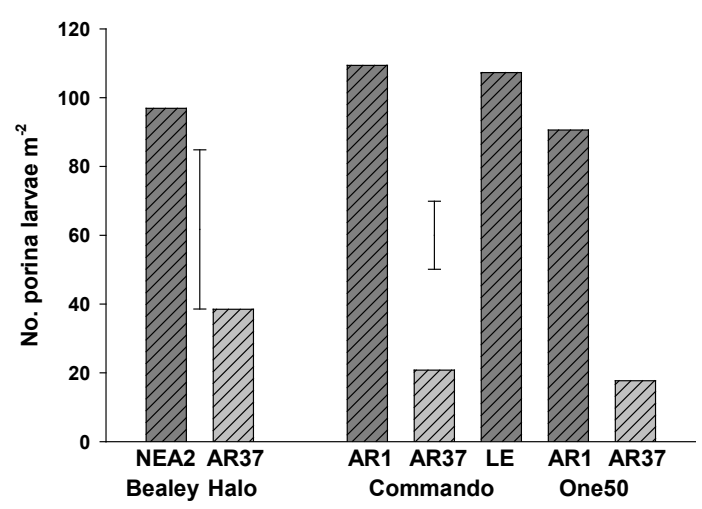

Figure 1. Estimated density of porina larvae in two tetraploid and two diploid perennial ryegrass cultivars infected with different endophytes in trials at Woodstock in Canterbury sampled in July 2011. Error bar $=$ LSD $(5 \%)$.

'Commando' LE (Table 2). Neither feeding damage nor plant density scores differed between the AR1 and LE treatments.

\section{Discussion}

These two field trials have confirmed pot trial results (Jensen \& Popay 2004) that AR37 provides its host ryegrass with resistance to porina, reducing populations to low levels with concomitant reductions in plant damage. No porina were found in AR37 plots in the Ceres Farm Trial in which there was low porina pressure in Nil and AR1 plots. In the Woodstock Trial much lower porina populations were present in AR37infected treatments than in those infected with other endophytes or with a low level of endophyte infection. Although porina populations were not estimated in 'Arrow', 'Alto' and 'Revolution' infected with AR1 at Woodstock, plant damage and density scores suggested that porina numbers were as high in these plots as in 'Commando' and 'One50'AR1. There were indications, however, that AR37-mediated resistance was less strong in the tetraploid 'Halo' which had almost twice the porina density of the two diploid cultivars.

The high densities of porina in AR1, LE and NEA2 treatments had resulted in visible damage in all these plots with plant thinning, tiller loss and browning of damaged tillers. Observations suggest that the porina larvae were still feeding and many were not yet close to maturity (probably a mixed population of Wiseana copularis and $W$. cervinata), so damage was likely to have increased in these plots after they were sampled. The lower porina populations in the diploid AR37 treatments were reflected in low plant damage scores and higher plant densities in those plots. Despite the 
higher populations in 'Halo' the damage to these plots also appeared to be minimal and plant densities were high. In the previous pot study by Jensen \& Popay (2004) those porina that survived on AR37-infected ryegrass had significantly lower weights than those in other treatments and caused minimal damage to plants after the first week of the experiment. Thus, while porina appear to be surviving on 'Halo' AR37, they were likely to be smaller and feeding less than those on 'Bealey' NEA2. Further work comparing the effects of diploids and tetraploids is warranted.

Over an 8-month period that included the major period of larval damage and a post-damage recovery period, the percentage reduction in pasture growth attributed to porina has been estimated to be equal to half the porina density at the beginning of the period (Barlow 1985b). On this basis, the porina densities in the Woodstock trial would have reduced ryegrass yields by approximately $50 \%$. Although there were significant differences in plant damage and density scores, yield data did not support a $50 \%$ loss in pasture production for those treatments that were severely affected by porina (data not presented). Grass grub damage had been observed in autumn prior to the porina damage which was likely to have affected all treatments equally.

Ryegrass infected with AR37 is highly deterrent to porina, probably due to the presence of epoxyjanthitrem alkaloids produced by the fungus. Both these trials were pure ryegrass swards whereas most pastures contain other plant species, particularly white clover, on which porina feed. The effect of alternative food sources on porina survival and damage in a sward dominated by ryegrass infected with AR37 is unknown. In the Ceres Farm trial, however, no porina larvae were found in AR37 plots in which $20 \%$ of plants were not infected. Similarly, in the Woodstock trial, 'Commando' AR37 plots comprised of $75 \%$ infected plants and $25 \%$ endophyte-free gave the same level of control of porina larvae as the 'One50' AR37 with 85\% infected plants and $15 \%$ endophyte-free. Furthermore, there was a high degree of damage delineation along borders of AR37 plots suggesting that these plots were not being invaded by porina larvae from adjacent susceptible treatments. Nevertheless further field work is necessary to be certain that porina populations are significantly reduced and damage alleviated in mixed species swards.

Current control options for porina are mainly centred on application of diflubenzuron, an insecticide that inhibits moulting of porina larvae (Ferguson 2000). It is particularly effective when applied to young larvae before damage becomes obvious, delivering economic benefits, without environmental consequences, for farms that are frequently affected by porina damage. These trials have shown that using AR37-infected ryegrass can be another effective option for reducing porina damage. In the Ceres Farm trial AR37 also had significantly lower populations of the sap-sucking root aphid, Aploneura lentisici, an effect that has been observed previously (Popay \& Gerard 2007; Hume et al. 2007). This endophyte also provides control of Argentine stem weevil (Listronotus bonariensis) larvae (Popay \& Thom 2009), and another sap sucking insect that reduces ryegrass vigour, pasture mealybug (Balanococcus poae), (Pennell et al. 2005). AR37infected ryegrass can cause ryegrass staggers in sheep, although incidence in 'Grasslands Nui' and the breeding line GA66 (related to 'Grasslands Samson') has been reported as being usually milder and less frequent than that caused by the Wild-type or common strain of endophyte (Fletcher \& Sutherland 2009). The control of several different insect pests increases both yield and persistence of ryegrass infected with this endophyte (Hume et al. 2007; Popay \& Thom 2009; Popay \& Hume 2011).

\section{ACKNOWLEDGEMENTS}

PGGWrightsons staff are thanked for their assistance with sampling the Ceres Farm Trial. Vanessa Scott is thanked for statistical analyses. This research is funded by Grasslanz Technology and PGGWrightson Seeds.

\section{REFERENCES}

Barlow, N.D. 1985a. Laboratory studies on porina (Wiseana spp.) feeding behaviour: the 'functional response' to herbage mass. Proceedings of the 4th Australasian Conference on Grassland Invertebrate Ecology: 1-6.

Barlow, N.D. 1985b. A model for pest assessment in New Zealand sheep pastures. Agricultural Systems 18: 1-37.

Barratt, B.I.P.; van Toor, R.F.; Ferguson, C.M.; Stewart, K.M. 1990. Grass grub and porina in Otago and Southland. A Guide to Management and Control. MAF, Dunedin. 104 pp.

Cottier, W. 1953. Aphids of New Zealand. 382 pp.

Dugdale, J.S. 1994. Fauna of New Zealand No 30 Hepialidae (Insecta: Lepidoptera). Manaaki Whenua Press, Christchurch. 164 pp.

Farrell, J.A.K.; Sweney, W.J.; Jones, A.E. 1974. Plant resistance to the porina caterpillar Wiseana cervinata (Lepidoptera Hepialidae). I Resistance in legumes and grasses. New Zealand Journal of Agricultural Research 17: 373-378.

Ferguson, C.M. 2000. Susceptibility of Wiseana species to diflubenzuron and implications for field applications. New Zealand Plant Protection 53: 430435. 
Fletcher, L.R.; Sutherland, B.L. 2009. Sheep responses to grazing ryegrass with AR37 endophyte. Proceedings of the New Zealand Grassland Association 71: 127-132.

Hume, D.E.; Ryan, D.L.; Cooper, B.M.; Popay, A.J. 2007. Agronomic performance of AR37-infected ryegrass in northern New Zealand. Proceedings of the New Zealand Grassland Association 69: 201205.

Jensen, J.G.; Popay, A.J. 2004. Perennial ryegrass infected with AR37 endophyte reduces survival of porina larvae. New Zealand Plant Protection 57: 323-328.

Pennell, C.G.L.; Popay, A.J.; Ball, O.J.-P.; Hume, D.E.; Baird, D.B. 2005. Occurrence and impact of pasture mealybug (Balanococcus poae) and root aphid (Aploneura lentisci) on ryegrass (Lolium spp.) with and without infection by Neotyphodium fungal endophytes. New Zealand Journal of Agricultural Research 48: 329-337.
Popay, A.J.; Gerard, P.J. 2007. Cultivar and endophyte effects on a root aphid, Aploneura lentisci, in perennial ryegrass. New Zealand Plant Protection 60: 223-227.

Popay, A.J.; Hume, D.E. 2011. Endophytes improve ryegrass persistence by controlling insects $I n$ : Pasture Persistence Symposium. Grassland Research and Practice Series No. 13: 149-156.

Popay, A.J.; Thom, E.R. 2009. Endophyte effects on major insect pests in Waikato dairy pasture. Proceedings of the New Zealand Grassland Association 71: 121-126.

Pottinger, R.P. 1968. Comments on the ecology of grass grub and porina caterpillar. Proceedings of the New Zealand Grassland Association 30: 102-113. 
